\title{
Clinical Profile of Diabetic Ketoacidosis among Children in Eastern Nepal
}

\author{
Dipak Muktan, ${ }^{1}$ Lisa Tamang Ghising, ${ }^{2}$ Rupa Rajbhandari Singh ${ }^{1}$ \\ ${ }^{1}$ Department of Pediatrics, B.P. Koirala Institute of Health Sciences (BPKIHS), Dharan, Nepal, ${ }^{2}$ Star Hospital, Lalitpur, \\ Nepal.
}

\begin{abstract}
Background: Diabetic ketoacidosis (DKA) is a life threatening complication which is the most common reason for hospital admission in children with Type 1 Diabetes. This study was carried out to determine the clinical characteristics of children admitted with Diabetic Ketoacidosis. Methods: Descriptive retrospective study was conducted at B.P. Koirala Institute of Health Sciences (BPKIHS), Dharan, Nepal. A total of 25 children of less than 20 years old diagnosed with Diabetic ketoacidosis who were admitted to the pediatric ward and pediatric intensive care unit from January 2013to December 2017were included in the study. Data were collected via hospital records of patients. Results: The mean age at presentation was $10.5 \pm 4.5$ years. Sixteen $(64 \%)$ children were newly diagnosed as diabetes while, nine $(36 \%)$ children were known cases of diabetes. The most common precipitating factor for DKA was omission of insulin $6(24 \%)$. Twelve (48\%) children had presented with severe DKA. Polyuria $23(92 \%)$ was the commonest symptom followed by polydipsia $22(88 \%)$, weight loss $17(68 \%)$,abdominal pain $13(52 \%)$, vomiting $13(52 \%)$ and unconsciousness $8(32 \%)$. The mean duration of symptoms before presentation was $11.3 \pm 5.7$ days. Mean $\mathrm{HbAlc}$ at presentation was $10.4 \pm 2.2$. Conclusions: Majority of the patients was newly diagnosed as diabetes who presented with Diabetic ketoacidosis. Omission of insulin was the main precipitating factor. Polyuria was the most common presenting symptom. Proper follow up care of diabetes and community awareness programs should be emphasized to reduce the incidence of Diabetic ketoacidosis.
\end{abstract}

Keywords: awareness; diabetic ketoacidosis; insulin; Type 1 diabetes mellitus.

\section{INTRODUCTION}

Type 1 Diabetes Mellitus is the most common form of diabetes in children ( $<20$ years of age) and more than 1.1 million children and adolescent are currently living with this chronic disease globally. ${ }^{1}$ Diabetic ketoacidosis (DKA) is an acute life threatening complication of Type 1 Diabetes mellitus leading to frequent hospital admission which requires prompt management. Incidence of Diabetic ketoacidosis in newly diagnosed Type 1 Diabetes mellitus is about $25-70 \%$ and the risk of developing Diabetic ketoacidosis in known Type1Diabetes children is $1-8 \%$ per patient per year. ${ }^{2-5}$ Diabetic ketoacidosis, which is associated with high risk of morbidity and mortality, is due to insulin deficiency and excess counter-regulatory hormones causing hyperglycemia, ketonemia, metabolic acidosis, dehydration and electrolyte disturbance. ${ }^{6,7}$

In Nepal, because of lack of awareness of diabetes especially in parents of rural areas, symptoms of diabetes are usually overlooked. Proper treatment of established Diabetes and knowledge among parents regarding its symptoms are very important to reduce the incidence of Diabetic ketoacidosis. Although a lot of studies regarding Diabetic ketoacidosis have been carried out so far in many countries including Nepal, we conducted this study in Eastern region of Nepal as there is paucity of published studies in pediatric Diabetic ketoacidosis. So, this study was carried out to determine the clinical characteristics of children admitted with Diabetic Ketoacidosis in BPKIHS Hospital, a tertiary care center for Eastern Nepal.

\section{METHODS}

Descriptive retrospective study was conducted at B.P. Koirala Institute of Health Sciences (BPKIHS), Dharan, Nepal, a tertiary care center for eastern part of Nepal, from January 2013 to July 2017.All children with diagnosis of Diabetic ketoacidosis were included in the study. Total 25 children were admitted in pediatric ward and pediatric intensive care unit with diagnosis of Diabetic ketoacidosis. Case records were studied and information details about demographics, clinical presentation, predisposing factors were recorded using a pre designed proforma. Confidentiality of the collected data was maintained. Diabetic ketoacidosis was diagnosed when the blood sugar at admission was $>200 \mathrm{mg} / \mathrm{dl}$ with acidosis $(\mathrm{pH}<7.3$ or plasma bicarbonate $<15$

Correspondence: Dr. Dipak Muktan, Department of Pediatrics, B.P. Koirala Institute of Health Sciences (BPKIHS), Dharan, Nepal. Email: deepak.moktan9@gmail.com. Phone: +977-9842587322. Article received: 2018-12-08. Article accepted: 2019-11-15. 
$\mathrm{mmol} / \mathrm{L}$ ) and positive urine ketones and hence, classified as mild, moderate and severe. Mild$\mathrm{pH}<7.3$ or bicarbonate $<15 \mathrm{mmol} / \mathrm{L}$; Moderate$\mathrm{pH}<7.2$ or bicarbonate $<10 \mathrm{mmol} / \mathrm{L}$; Severe- $\mathrm{pH}$ $<7.1$ or bicarbonate $<5 \mathrm{mmol} / \mathrm{L}^{8}{ }^{8}$ Children were categorized as newly diagnosed diabetes if they were previously undiagnosed but later on presented with Diabetic ketoacidosis. Diabetic ketoacidosis was managed as per International Society for Pediatric and Adolescent Diabetes (ISPAD) guideline. All patients were monitored every hour for vitals and clinical signs (heart rate, respiratory rate, blood pressure, urine output, oxygen saturation, sensorium, headache, vomiting), every 2 hours for blood sugar and every 4 hours for arterial/ venous blood gas analysis, serum electrolytes. Renal function test was assessed every 12 hours. Modified Kuppuswamy scale was used to assess socioeconomic status. ${ }^{9}$ Blood glucose was measured in a hospital laboratory from venous sample. $\mathrm{HbAlc}$ was measured using an automated analyzer (Cobas, Hitachi, Japan). Data was entered in Excel and analyzed by using SPSS version 20. The quantitative variables were presented in the form of mean, standard deviation and range. Categorical variables were expressed in frequency and percentage. The study proposal was approved by Institutional Research Ethical Committee (IRC) of the hospital.

\section{RESULTS}

Total 25 children below 20 years of age were admitted over this study period with diagnosis of Diabetic ketoacidosis. Among them, 15 (60\%) were female and $10(40 \%)$ were male. Most of the children $18(72 \%)$ belonged to rural areas and remaining $7(28 \%)$ belonged to urban areas. The mean age at presentation was $10.5 \pm 4.5$ years, out of which $18(72 \%)$ were from lower middle socioeconomic status and remaining $7(28 \%)$ were from middle socio-economic status. Six (24\%) children had family history of diabetes. Clinical characteristics have been shown in (Table 1).

During presentation in the hospital, polyuria 23 $(92 \%)$ was found to be the commonest symptom followed by polydipsia $22(88 \%)$, weight loss 17 $(68 \%)$, abdominal pain $13(52 \%)$, vomiting 13 $(52 \%)$ and unconsciousness $8(32 \%)$. The mean duration of symptoms before presentation was 11.3 \pm 5.7 days. Mean HbAlc at presentation was $10.4 \pm$ 2.2. The most common precipitating factor for DKA was skipping of insulin $6(24 \%)$ followed by infections $3(12 \%)$ as shown in figure1. Sixteen (64\%) children were newly diagnosed diabetes who presented in Diabetic ketoacidosis. Two children had pneumonia whereas one had urinary tract infection. In most of the cases, primary caregiver was mother 12 (48\%), among them only $4(33.3 \%)$ had formal education (Figure 1).

\begin{tabular}{|c|c|}
\hline Variables & Frequency(\%) \\
\hline $\begin{array}{l}\text { Age at presentation of DKA } \\
\text { (yr.), mean } \pm \mathrm{SD} \text {, (range) }\end{array}$ & $10.5 \pm 4.5$ years $(4-20$ years \\
\hline Residence & \\
\hline Rural & $18(72)$ \\
\hline Urban & $7(28)$ \\
\hline Severity & \\
\hline Severe & $12(48)$ \\
\hline Moderate & $8(32)$ \\
\hline Mild & $5(20)$ \\
\hline Socio-economic status & \\
\hline Lower middle & $18(72)$ \\
\hline Middle & $7(28)$ \\
\hline Presenting complaints & \\
\hline Polyuria & $23(92 \%)$ \\
\hline Polydipsia & $22(88 \%)$ \\
\hline Weight loss & $17(68 \%)$ \\
\hline Abdominal pain & $13(52 \%)$ \\
\hline Vomiting & $13(52 \%)$ \\
\hline Unconsciousness & $8(32 \%)$ \\
\hline $\begin{array}{l}\text { Duration of symptoms } \\
\text { (days), mean } \pm \text { SD }\end{array}$ & $11.3 \pm 5.7$ \\
\hline Family history DM & $6(24)$ \\
\hline $\begin{array}{l}\text { HbA1c at presentation } \\
(\%) \text {, mean } \pm \text { SD }\end{array}$ & $10.4 \pm 2.2$ \\
\hline Primary caregiver & \\
\hline Mother & $12(48)$ \\
\hline Both mother and father & $6(24)$ \\
\hline Father & $5(20)$ \\
\hline Brother & $1(4)$ \\
\hline Sister & $1(4)$ \\
\hline
\end{tabular}

\section{DISCUSSION}

Diabetic ketoacidosis is the most common complication of Type 1 Diabetes leading to frequent hospital admission which has many precipitating factors. In the present study, there was female preponderance $15(60 \%)$ which is in concordance with other studies. ${ }^{10,11}$ The mean age at presentation in our study was $10.5 \pm 4.5$ years which is similar to other studies from North India (11.4 \pm 4.4 years) and Brazil (10.2 \pm 2.9 years). ${ }^{12,13}$

However, some other studies showed younger age at presentation. ${ }^{14,15} \mathrm{In}$ our study, $16(64 \%)$ children were newly diagnosed as diabetes who presented in Diabetic ketoacidosis which is similar to a study

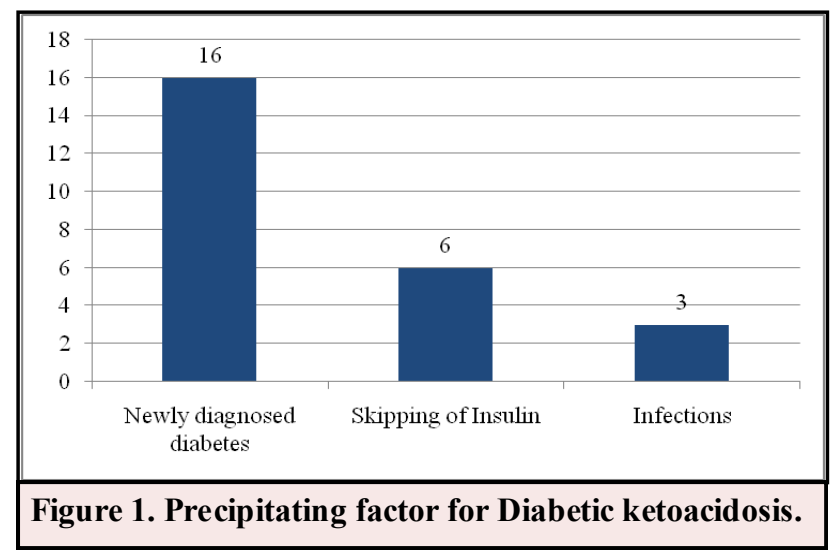


$(63.5 \%)$ done in tertiary care hospital of South India. ${ }^{16}$ In contrast, some other studies, North India $(48.2 \%)$, Iraq $(26.7 \%)$ showed less percentage of newly diagnosed diabetes who presented in DKA. ${ }^{17,18}$

The older age at presentation and high incidence of DKA in newly diagnosed diabetes in our region is probably due to delay in hospital visit and lack of awareness of diabetic symptoms among parents. Twelve $(48 \%)$ children had presented with severe DKA followed by moderate (32\%) and mild (20\%) DKA. This finding is comparable to the studies done in tertiary care hospital in India. ${ }^{17,19}$ How ever, a study from India showed higher percentage of mild DKA $(59.6 \%)$ followed by moderate $(19.2 \%)$ and severe $(21.2 \%)$ DKA. In our study, the commonest symptom was polyuria $23(92 \%)$ followed by polydipsia $22(88 \%)$, weight loss 17 $(68 \%)$, abdominal pain $13(52 \%)$, vomiting 13 $(52 \%)$ and unconsciousness $8(32 \%)$ which is comparable to other studies. ${ }^{19,20}$ Six $(24 \%)$ children had family history of diabetes in first degree relative which is less in comparison to a study $(61.5 \%)$ done in South India. ${ }^{16}$ Majority of patients were from rural areas $18(72 \%)$ which is similar to a study done in South India $(78 \%) .{ }^{16}$ However, studies from Iraq (64.7\%) and Iran (61.1\%) have shown dominance of children from urban areas. ${ }^{1821}$ According to modified Kuppuswamy scale, $18(72 \%)$ were from lower middle and remaining $7(28 \%)$ were from middle socio economic status in our study. But a study from India revealed that the majority of children (78\%) belonged to lower socioeconomic status. ${ }^{19}$ These variations may be due to inadequate access to healthcare center. In our set up, being a tertiary health care center, all patients from different socioeconomic status visit the hospital. But, people from good socio economic status and urban areas usually visit private health care facilities. Mean HbAlc at presentation in our study was $10.4 \pm 2.2$ which is comparable to a study done in a tertiary care center of North India $(11.6 \pm 2.4) .{ }^{17}$ Our study showed that skipping of insulin $6(24 \%)$ was the most common precipitating factor for DKA followed by infections $3(12 \%)$. Sixteen (64\%) children were newly diagnosed diabetes who presented in Diabetic ketoacidosis. These findings are in concordance with the studies done in Iran and India. ${ }^{16,21}$ In present study, the main primary caregiver was mother $12(48 \%)$ followed by both mother and father $6(24 \%)$,father $5(20 \%)$, sister $1(4 \%)$ and brother $1(4 \%)$. Among them, only $12(24 \%)$ could read and write. In contrast to these findings, a study from Ethiopia revealed that only $8.9 \%$ caregivers could not read and write as most of the children resided in urban areas, whereas in our study, majority of children resided in rural areas. ${ }^{22}$

As this study is carried out in a tertiary care center of eastern Nepal with small sample size, these findings cannot be generalized to all pediatric diabetic ketoacidosis population of the country. Therefore, multicenter large studies are required to describe the characteristics of pediatric diabetic ketoacidosis of the country.

\section{CONCLUSIONS}

Diabetic ketoacidosis is a life threatening complication of diabetes mellitus in children. Newly diagnosed cases of diabetes were more than previously diagnosed cases who presented in Diabetic ketoacidosis. Skipping of insulin was the commonest triggering factor. The most common presenting symptom was polyuria followed by polydipsia, weight loss, abdominal pain and vomiting. In order to diminish the incidence of Diabetic ketoacidosis, prompt management of diabetes and community awareness programs should be emphasized.

\section{REFERENCES}

1. International Diabetes Federation. IDF diabetes atlas. Eighth edition 2017

2. Faich GA, Fishbein HA, Ellis SE. The epidemiology of diabetic acidos is: a population-based study. Ame J Epidemiol. 1983;117(5):551-8.

3. Reddy Y, Ganie Y, Pillay K. Characteristics of children presenting with newly diagnosed type 1 diabetes. S Afr J Child Health 2013; 7: 46-48 [DOI: 10.7196/SAJCH.500].

4. Usher - Smith JA, Thompson M, Ercole A, Walter FM. Variation between countries in the frequency of diabe-tic ketoacidos is at first presentation of type 1 diabetes in children: a systematic review. Diabetologia 2012; 55: 2878-94.

5. Dunger DB, Sperling MA, Acerini CL, et al. European Society for Paediatric Endocrinology/ Lawson Wilkins Paediatric Endocrine Society consensus statement on diabetic ketoacidosis in children and adolescents. Arch Dis Child

\section{4;89:188-194.}

6. Center for Disease Control (CDC). Hospitalizations for diabetic Ketoacidos is: Washington State, 19871989. MMR-Morb Mortal Wkly Rep. 1992;41 (44):837-9.

7. Patel NR. Diabetic Ketoacidos is in the Pediatric Patient. Indian J Pediatr. 2002;69(1):75-7.

8. Wolfsdorf JI, Algrove J, Craig ME, et al. A Consensus statement from the intemational society for pediatric and adolescent diabetes. Diabetes ketoacidos is and hyperglycemia and hyperosmolar state. Pediatric Diabetes 2014;15(Supp1 20):154-179.

9. Singh T, Sharma S, Nagesh S. Socio-economic status scales updated for 2017. Int J Res Med Sci 2017;5:3264-7.

10. Nur Rochmah, Muhammad Faizi and Netty Harjantien; Diabetic Ketoacidos is in children: an 11yearretrospective in Surabaya, Indonesia. Paediatrica Indonesiana, Vol. 55, No. 1, January 2015: 40-43.

11. Neu A, Willasch A, Ehehalt S, Hub R, Ranke MB, 
Becker SA, Ketoacidos is at onset of type 1 diabetesmellitus in children-frequency and clinical presentation. Pediatr Diabetes. 2003;4:77-81.

12. Bhardwaj P, Yadav V, Sharma M. Clinical profile and outcome of the children with diabetic ketoacidos is (DKA) in hilly Himalayan state of north India. Int J Res Med Sci 2017;5:5402-5.

13. Lopes CL, Pinheiro PP, Barberena LS, et al. Diabetic ketoacidos is in a paediatric intensive care unit. J Pediatr (Rio J)2017;93(2):179-184.

14. Jayashree M, Singhi S. Diabetic ketoacidos is: Predictors of outcome in a pediatric intensive care unit of a developing country. Pediatr Crit Care Med. 2004;5:427-33.

15. Jahagirdar RR, Khadilkar VV, Khadilkar AV, Lalwani SK. Management of diabetic ketoacidos is in PICU. Indian J Pediatr. 2007;74:551-4.

16. Padma BK, Antony JM Diabetic ketoacidos is in children - Clinical profile and outcome. J.Evid.Bas edMed.Healthc.2017;4(93),5697-5702. DOI: $10.18410 /$ jebmh/2017/1144.

17. Bhardwaj P, Yadav V, Sharma M. Clinical profile and outcome of the children with diabetic ketoacidos is (DKA) in hilly Himalayan state of north India. Int J Res Med Sci 2017; 5:5402-5.
18. Abdulabbas Abduon Hadi, Mohammad Khawwam Abdulwahid, Nabil Fahim Abdulrazzaq. Clinical Profile of Pediatric Diabetic Ketoacidos is in Karbala City, IRAQ. Joumal of Natural Sciences Research www.iis te.org ISSN 2224-3186 (Paper) ISSN 22250921 (Online)Vol.6, No.10, 2016.

19. Basavanthappa SP, Pejaver R, Raghavendra K, Srinivasa V, Suresh Babu MT. Clinical profile and outcome of diabetic ketoacidos is in a tertiary care hospital in South India. Int $\mathbf{J}$ Contemp Pediatr 2015;2:29-31.

20. Ahmed S, Jan M, Rashid I, et al. Clinical profile and outcome of paediatric patients with diabetic ketoacidos is. IOSR Joumal of Dental and Medical Sciences 2015;14(3):22-26.

21. Zahra Razavi, Farimehr Hamidi. Diabetic Ketoacidosis: Demographic Data, Clinical Profile and Outcome in a Tertiary Care Hospital. Iran J Pediatr. In Press(In Press):e7649.

22. Helen Siyoum Atkilt, Muluken Gizaw Turago, Balewgizie Sileshi Tegegne. Clinical Characteristics of Diabetic Ketoacidos is in Children with Newly Diagnosed Type 1 Diabetes in Addis Ababa, Ethiopia: A Cross-Sectional Study. PLOS ONE DOI:10.1371/journal.pone.0169666.

Citation: Muktan D, Ghising LT, Singh RR. Clinical Profile of Diabetic Ketoacidosis among Children in Eastern Nepal. JCMS Nepal. 2019; 15(4):226-9. 